\title{
Molecular Orbital Calculation of $\pi$-Bond Order and Charge Distribution in the 3- and 4-Phenyl-1,2-dithiolium Ions
}

\author{
ASBJøRN HORDVIK and EINAR SLETTEN \\ Chemical Institute, University of Bergen, Bergen, Norway
}

\begin{abstract}
The $\pi$-electron structures of the 4-phenyl-1,2-dithiolium ion (I) and the 3-phenyl-1,2-dithiolium ion (II) have been derived by means of an improved Hückel method. The results are discussed in relation to bond length data and UV spectra for the ions.

The phenyl substituent perturbs to a small degree the $\pi$-electron structure of the 1,2-dithiolium ring. With respect to (I) a slight quinoid character is indicated from the MO calculations as well as from the structure determinations. The observed red shift for (II) relative to (I) from UV spectra of their hydrogen sulphates in $0.1 \mathrm{M}$ $\mathrm{HCl}$ solution, may be explained by assuming that (I) is twisted in solution.

A $\pi$-bond-order/bond-length relationship for $\mathrm{S}(\mathrm{II})-\mathrm{C}\left(s p^{2}\right)$ bonds is proposed.
\end{abstract}

Rergson $^{1}$ in 1962 derived a simple solution of the self-consistent parameter B problem in MO-LCAO theory, by assuming the following relationship between atom and bond parameters and the charge-bond-order matrix $(\mathbf{Q})$ :

$$
\left(\mathbf{H}^{\mathrm{n}}\right)_{\mu \nu}=(\mathbf{A})_{\mu \nu}+(\mathbf{B})_{\mu \nu} \cdot\left(\mathbf{Q}^{\mathrm{n}-1}\right)_{\mu \nu}
$$

where $\mathbf{A}$ and $\mathbf{B}$ depend on the particular atoms and bonds involved.

One starts with a matrix $\left(\mathbf{H}^{\circ}\right)$ comprising a convenient set of parameters, performs the Hückel calculations, adjusts the parameters according to the above relationship, and iterates until a consistent set of parameters has been obtained.

This improved Hückel method has been applied by Bergson ${ }^{1}$ for the calculation of the electronic structures of some sulphur heterocycles, among them the unsubstituted 1,2-dithiolium ion which is known as a pseudo-aromatic system.

The molecular structures of 3-phenyl-1,2-dithiolium iodide, and of 4-phenyl1,2-dithiolium iodide, bromide, chloride monohydrate, and thiocyanate have been determined in this institute by X-ray methods. ${ }^{2-6}$ UV spectra of 4- and 3-phenyl-1,2-dithiolium hydrogen sulphate in $0.1 \mathrm{M} \mathrm{HCl}$ solution have been 
published by Klingsberg. ${ }^{7}$ The principal absorption peaks for the two salts are found at $242 \mathrm{~m} \mu$ and at $356 \mathrm{~m} \mu$, respectively, and secondary absorption peaks are found at $345 \mathrm{~m} \mu$ and at $287 \mathrm{~m} \mu$, respectively. Klingsberg assumes that the observed bathochromic effect in the 3-phenyl relative to the 4-phenyl1,2-dithiolium ion is caused by enhanced resonance possibilities in the former. Thus the $\pi$-bonding in the carbon-carbon bond connecting the two rings should be more pronounced in the 3-phenyl isomer, which in fact is indicated from the results of the structure investigation. Thus the length of the mentioned carbon-carbon bond in 3-phenyl-1,2-dithiolium iodide ${ }^{2}$ has been found to be $1.40 \pm 0.04 \AA$.

The electronic characteristics of the 3- and 4-phenyl-1,2-dithiolium ions, from simple Hückel calculations, have recently been reported by Zarádnik and Párkányi. ${ }^{8}$ They find that the difference in energy between the highest occupied and lowest unoccupied $\pi$-molecular orbitals in the 3- and 4-phenyl isomers are 0.9368 and $0.9092 \beta$ units, respectively; $\beta$ here refers to the $\mathrm{C}-\mathrm{C}$ bond in benzene.

One might probably expect a phenyl substituent in 3- or 4-position in the 1,2-dithiolium ion only to a small degree to perturb the bonding conditions in the dithiolium ring. Thus the bond lengths in these ions should be about the same as in the unsubstituted ion. If the $\pi$-bond orders, calculated by Bergson ${ }^{1}$ for the different bonds in the unsubstituted 1,2-dithiolium ion, is used for predicting bond lengths in the disulphide rings of the two mono-phenyl isomers, there seems to be a very good fit with experimental values, as has been discussed elsewhere..$^{2,3}$

From the above we feel that Bergson's self-consistent parameter MO method may provide good descriptions of the electronic structures of sulphur heterocycles exhibiting aromatic character. This might in turn lead to relevant bond-length/bond-order relationships for $\mathrm{S}(\mathrm{II})-\mathrm{C}\left(s p^{2}\right)$ and $\mathrm{S}(\mathrm{II})-\mathrm{S}(\mathrm{II})$ bonds. With this view the present MO calculations of $\pi$-bond orders and charge distribution in the 3- and 4-phenyl-1,2-dithiolium ions have been undertaken.

The calculations were carried out on the IBM $1620^{\text {II }}$ computer, using a simple HMO program ${ }^{9}$ which was modified by us to do the iteration. Values of the matrix elements of $(\mathbf{A})_{\mu \nu}$ and $(\mathbf{B})_{\mu \nu}$ in (1) corresponding to the nonoverlap case have been derived by Bergson. ${ }^{1}$ These are, for the $S-S$ bond, based on Slater integrals from Mulliken's tables, ${ }^{10}$ for $\mathrm{C}-\mathrm{S}$ bonds matched with the bond-parameters recommended by Pullman, ${ }^{11}$ and for the $\mathrm{C}-\mathrm{C}$ bonds based on values for benzene and ethylene.

It seems obvious that in the case of the monophenyl-substituted 1,2-dithiolium ions, a relevant start for our calculations would be the electronic structure of benzene and of the 1,2-dithiolium ion as reported by Bergson.1 On this basis, a consistent set of parameters was obtained after four iterations.

The 4-phenyl isomer is found to be planar in the crystal, and in the 3phenyl isomer the planes of the two rings are twisted $27^{\circ}$ around the connecting $\mathrm{C}-\mathrm{C}$ bond. In order to allow for the reduced $\pi$-overlap in this bond, the cosine formula ${ }^{12}$ was applied. The resulting charge distributions and $\pi$-bond orders for the two ions are given in Scheme 1, together with Bergson's values for the unsubstituted ion (non-overlap case). ${ }^{1}$ Furthermore, the MO energy levels for (I) and (II) are listed in Table 1. With respect to (I), values are given both 


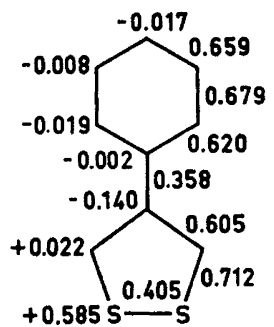

(I)

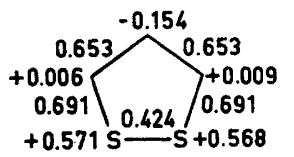

(III)

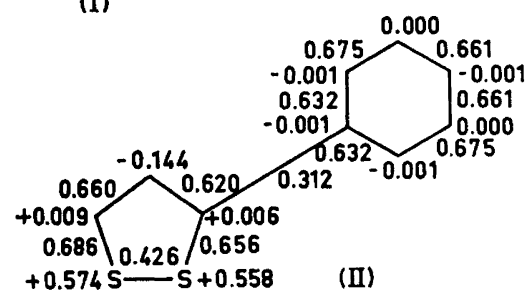

Scheme 1. Charge distributions and $\pi$-bond orders.

for a planar model and for one with the rings twisted $45^{\circ}$. The values for (II) correspond to a molecular model with ring twist of $30^{\circ}$.

Table 1. MO egergy levels for 4-phenyl-1,2-dithiolium ion (I) and for 3-phenyl-1,2-dithiolium ion (II). The energy unit refers to a carbon-carbon double bond.

\begin{tabular}{|c|c|c|c|c|c|c|c|c|c|c|c|}
\hline & $\psi_{1}$ & $\psi_{2}$ & $\psi_{3}$ & $\psi_{4}$ & $\psi_{5}$ & $\psi_{6}$ & $\psi_{7}$ & $\psi_{8}^{\prime}$ & $\psi_{9}$ & $\psi_{10}$ & $\psi_{11}$ \\
\hline (I) plans & 065 & 1.754 & 1.061 & 1.046 & 0.883 & 0.394 & -0.835 & -0.908 & -0.980 & -1.523 & -1.955 \\
\hline (I) $45^{\circ}$ twist & 2.049 & 1.756 & 1.042 & 1.040 & 0.883 & 0.411 & -0.843 & -0.906 & -0.981 & -1.522 & -1.930 \\
\hline (II) $30^{\circ}$ twist & 2.067 & 1.748 & 1.173 & 0.896 & 0.763 & 0.512 & -0.705 & -0.895 & -1.125 & -1.520 & -1.911 \\
\hline
\end{tabular}

\section{DISCUSSION}

A comparison of the charge distributions in the 4-phenyl-1,2-dithiolium ion (I) and the 3-phenyl-1,2-dithiolium ion (II) with that in the unsubstituted 1,2-dithiolium ion (III), indicates that the electronic structure of the 1,2dithiolium ring is perturbed by the phenyl substituents to a small degree. In (I) there seems to be a slight tendency towards quinoid character, which also the structure determinations of 4-phenyl-1,2-dithiolium salts indicate, ${ }^{3-6}$ although the relevant bond length differences are hardly significant. The $\pi$ bond orders derived for (II) indicate that the $\mathrm{C}-\mathrm{S}$ bond closest to the phenyl group should be somewhat longer than the other $\mathrm{C}-\mathrm{S}$ bond. The $\mathrm{C}-\mathrm{S}$ bond lengths in 3-phenyl-1,2-dithiolium iodide are, in agreement with this, found to be 1.71 and $1.67 \pm 0.03 \AA$, respectively. However, the electronic structure 
derived for (II) is not consistent with the found length of the central C-C bond (1.40 $\pm 0.04 \AA)$ in that compound.

On summing the electron energies for the six occupied molecular orbitals, cf. Table 1 , and using $65 \mathrm{kcal} / \mathrm{mole}$ as the energy unit, ${ }^{13}$ we find that the $\pi$ electron energy for (I) is about $6 \mathrm{kcal} / \mathrm{mole}$ lower than that for (II). The difference is reduced to about $3 \mathrm{kcal} / \mathrm{mole}$ when for (I) the MO calculations are based on a molecular model with the two rings twisted $45^{\circ}$ around the connecting $\mathrm{C}-\mathrm{C}$ bond.

The energy differences between the highest occupied and the lowest unoccupied molecular orbitals in $(\mathrm{I})$ is, according to the values in Table $1,1.229$ $\gamma_{0}$ for the planar model and $1.254 \gamma_{0}$ for the $45^{\circ}$ twisted model. For (II) the value is $1.217 \gamma_{0}$. The ratio between the energy unit usually employed, $\beta$ for $\mathrm{C}-\mathrm{C}$ in benzene, and $\gamma_{0}$ employed here which refers to a $\mathrm{C}-\mathrm{C}$ double bond, is 0.891 . With $\gamma_{0}=65 \mathrm{kcal} / \mathrm{mole},{ }^{13}$ these transition energies correspond to absorption peaks at 358,351 , and $361 \mathrm{~m} \mu$, respectively. As mentioned in the introduction, Klingsberg ${ }^{7}$ found absorption maxima at $345 \mathrm{~m} \mu$ (I) and 356 $\mathrm{m} \mu$ (II). The fit is considered quite good. The absorption maxima found at $242 \mathrm{~m} \mu$ (I) and $287 \mathrm{~m} \mu$ (II) may correspond to transitions from the next highest occupied to the lowest unoccupied level, calculated to be $254 \mathrm{~m} \mu\left(\mathrm{I}, 45^{\circ}\right)$ and $299 \mathrm{~m} \mu$ (II) from the values in Table 1. Furthermore, the observed redshift of the 3-phenyl-isomer relative to the 4-phenyl-isomer in solution, indicates from our calculations that the 4-phenyl isomer is twisted. This assumption seems reasonable on the basis of the ortho-hydrogen repulsion which tends to prevent a planar conformation in solution; cf. biphenyl in the solid and gaseous states. ${ }^{14,15}$ Although we recognize the limitations of MO methods for quantitative predictions as well as descriptions, we find it tempting to point to this striking fit.

Abrahams ${ }^{16}$ in 1956 published a curve for the dependence of $\mathrm{C}-\mathrm{S}$ bond length on double bond character, based on $1.61 \AA$ for $\mathrm{C}-\mathrm{S}$ double bond, $1.82 \AA$ for the $\mathrm{C}-\mathrm{S}$ single bond, and data based on thiophene for intermediate bond lengths. More accurate bond lengths data for thiophene are now available, as well as $\mathrm{C}-\mathrm{S}$ bond lengths in compounds where the electronic structures have been calculated by the present method. The points in Fig. 1 represent the $\mathrm{C}-\mathrm{S}$ bonds in 4-methyl trithione, thiophene, and the 3- and 4-phenyl1,2-dithiolium ions. The values are listed in Table 2. A curve has been tentatively drawn through the points and the values used by Abrahams ${ }^{16}$ for

Fig. 1. Proposed bond-length/bond-order curve for $\mathrm{S}(\mathrm{II})-\mathrm{C}\left(s p^{2}\right)$ bonds.

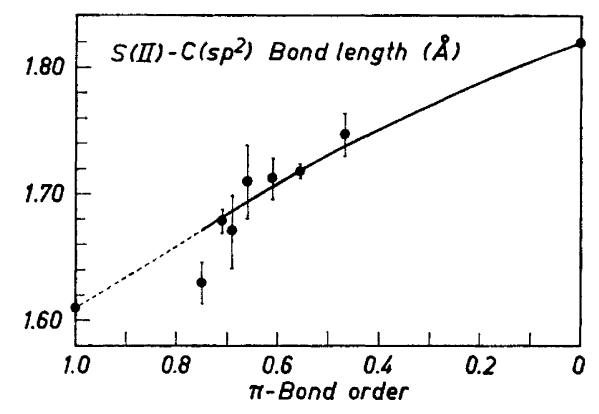

Acta Chem. Scand. 20 (1966) No. 7 
Table 2. Bond lengths and corresponding $\pi$-bond orders for $\mathrm{S}(\mathrm{II})-\mathrm{C}\left(s p^{2}\right)$ bonds.

\begin{tabular}{lcc}
\hline Compound & $\mathrm{C}-\mathrm{S}$ bond length $(\AA)$ & $\pi$-Bond order \\
4-Methyl-trithione ${ }^{17,1}$ & $1.747 \pm 0.017$ & 0.471 \\
" & $1.713 \pm 0.017$ & 0.612 \\
Thiophene $^{18}$ & $1.627 \pm 0.017$ & 0.747 \\
3-Phenyl-1,2-dithiolium ion ${ }^{2}$ & $1.718 \pm 0.005$ & 0.556 \\
4-Phenyl-1,2-dithiolium ion $^{6}$ & $1.71 \pm 0.03$ & 0.656 \\
& $1.67 \pm 0.03$ & 0.686 \\
& $1.678 \pm 0.008$ & 0.712
\end{tabular}

single and double bonds. The lower part of the curve is dashed, because we doubt whether it is justified to include data from thione groups. The graph in Fig. 1 deviates from that proposed by Abrahams ${ }^{16}$ only by being somewhat less curved.

Acknowledgement. The authors wish to thank Dr. J. J. Lindberg and Fil. Mag. V. J. Nummi, University of Helsingfors, for a copy of their HMO program, and we are also greatly indebted to Mr. Spjeld of the EDB Department, University of Bergen, for the necessary modifications of the program.

\section{REFERENCES}

1. Bergson, G. Arkiv Kemi 19 (1962) 181.

2. Hordvik, A. and Kjøge, H. M. Acta Chem. Scand. 19 (1965) 935.

3. Hordvik, A. and Sletten, E. Acta Chem. Scand. 20 (1966) 1874.

4. Hordvik, A. and Baxter, R. M. To be published.

5. Grundtvig, F. and Hordvik, A. To be published.

6. Hordvik, A. and Kjøge, H. M. To be published.

7. Klingsberg, E. J. Am. Chem. Soc. 83 (1961) 2934.

8. Zarádnik, R. and Párkányi, C. Collection Czech. Chem. Commun. 30 (1965) 3016.

9. Nummi, V. J. HMO program, University of Helsingfors, Department of Applied Mathematics.

10. Mulliken, R. S., Rieke, C. A., Orloff, D. and Orloff, H. J. Chem. Phys. 17 (1949) 1248.

11. Pullman, B. and Pullman, A. Rev. Mod. Phys. 32 (1960) 428.

12. Streitwieser, A., Jr. Molecular Orbital Theory for Organic Chemists, Wiley, New York 1961.

13. Bergson, G. Arkiv Kemi 19 (1962) 265.

14. Almenningen, A. and Bastiansen, O. Kgl. Norske Videnskab. Selskabs, Skrifter 1958 No. 4.

15. Trotter, J. Acta Cryst. 14 (1961) 1135.

16. Abrahams, S. C. Quart. Rev. (London) 10 (1956) 407.

17. Jeffrey, G. A. and Shiono, R. Acta Cryst. 12 (1959) 447.

18. Bak, B., Christensen, D., Rastrup-Andersen, J. and Tannenbaum, E. J. Chem. Phys. 25 (1956) 892.

Received March 26, 1966. 